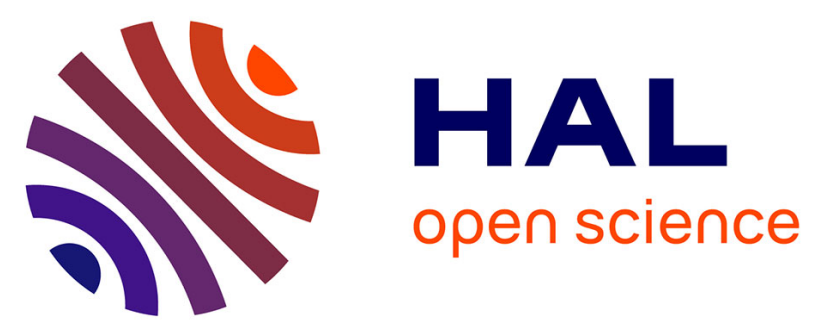

\title{
Use of Distributed Optical Fibre to Monitor the Crack Propagation of an Adhesively Bonded Joint During an ENF Test
}

Quentin Sourisseau, Emilie Lepretre, Sylvain Chataigner, Xavier Chapeleau, Luc Mouton, Stéphane Paboeuf

\section{To cite this version:}

Quentin Sourisseau, Emilie Lepretre, Sylvain Chataigner, Xavier Chapeleau, Luc Mouton, et al.. Use of Distributed Optical Fibre to Monitor the Crack Propagation of an Adhesively Bonded Joint During an ENF Test. CICE 2021 - 10th International Conference on FRP Composites in Civil Engineering, Dec 2021, Istanbul, Turkey. pp.253-265, 10.1007/978-3-030-88166-5_21 . hal-03507675

\section{HAL Id: hal-03507675 \\ https://hal.inria.fr/hal-03507675}

Submitted on 3 Jan 2022

HAL is a multi-disciplinary open access archive for the deposit and dissemination of scientific research documents, whether they are published or not. The documents may come from teaching and research institutions in France or abroad, or from public or private research centers.
L'archive ouverte pluridisciplinaire $\mathbf{H A L}$, est destinée au dépôt et à la diffusion de documents scientifiques de niveau recherche, publiés ou non, émanant des établissements d'enseignement et de recherche français ou étrangers, des laboratoires publics ou privés. 


\title{
Use Of Distributed Optical Fibre To Monitor The Crack Propagation Of An Adhesively Bonded Joint During An ENF Test.
}

\author{
Quentin Sourisseau $^{1,2,3}$, Emilie Lepretre ${ }^{1}$, Sylvain Chataigner ${ }^{1}$, Xavier Chapeleau ${ }^{2}$, Luc Mouton ${ }^{3}$, \\ Stéphane Paboeuf ${ }^{3}$ \\ ${ }^{1}$, Univ Gustave Eiffel, MAST-SMC Bouguenais, France, ${ }^{2}$ Univ Gustave Eiffel, Inria, COSYS-SII, I4S \\ Team, Bouguenais, France ${ }^{3}$ Bureau Veritas Marine \& Offshore, Expertise Department, Nantes, \\ France
}

\begin{abstract}
:
The floating production, storage and offloading units (FPSO) being generally in a tropical area, makes corrosion a fundamental ageing problem of these steel structures. Therefore, there is a strong need for proposing repair solutions having low impact on their exploitation. The owner of these units are highly interested in the development of "cold repair" in contrast with "hot works" which require to stop the production for security risks, like adhesively bonded FRP (Fibre Reinforced Polymer) patch which requires additional development, in particular in the design step. The design of these reinforcements needs a complete understanding of the mechanical state of the patch which is based on the different materials and interfaces properties. Fracture mechanics seems an interesting option to express the mechanical state of the patch and more particularly the risk to undergo interlaminar fracture or steel interface debonding failure before materials failure. The experimental definition of the required design values for such an approach (critical toughnesses) are generally obtained with common tests such as DCB or ENF tests.

The presented study is focused on the determination of the critical toughness in mode II through ENF (End Notched Flexure) test which can be done following some standards, such as ASTM D7905. A distributed optical fibre was used to verify the correct determination of the initial crack length, to determine the crack propagation during the test, and to monitor the fracture process zone length. The currently used methods, such as visual observation or Digital Image Correlation (DIC) of the crack front at the border of the sample, may indeed induce error if the crack is not straight. To compare these methods, the realized test was monitored using a distributed optical fibre placed in the centre of the lap width, in and on the specimen. Firstly, the issues related to the integration of this continuous optical fibre will be raised (insertion, precision resolution, measurement noise). Then, some experimental investigations will be described presenting different monitoring strategies using continuous optical fibre measurement and Digital Image Correlation technique (DIC). The obtained results will be analyzed focusing on the proper determination of the critical toughness of the adhesive. This will then be used to design and optimize the monitoring strategy of a wider experimental campaign.
\end{abstract}

\section{Keywords:}

Adhesive bonding, fracture mechanics, optical fibre, ENF, experimental investigations.

\section{Introduction:}

The maintenance of steel structure installed in harsh offshore environment (like tropical areas) is a great challenge. Vessels and mobile offshore units can be maintained and repaired onshore in shipyards, but fixed units, such as platforms or FPSO structures, do not come back in dry dock and shall be maintained at sea. On FPSO units/structures, the corrosion is a permanent threat due to high temperature and high humidity conditions. The development of new technique to repair those decks are actually in development, more particularly bonded repair solution which presents several advantages (short downtime and non-intrusively process). For this reason, the JIP StrengthBond Offshore project initiated by 
Bureau Veritas Marine \& Offshore (BV) has been launched in March 2019. The project aims to achieve the following main objectives:

- Validate the characterization procedure for strength determination of bonded assembly,

- $\quad$ Standardize the qualification process for offshore composite bonded repairs.

- $\quad$ Define a robust strength prediction method,

- Enable a better evaluation of the margin between the actual strength of a repair and the design load.

Repairing a corroded deck of a ship shape unit imposes an important constraint on the design. The patch lies in an area that is fully subjected to hull girder stress, causing high stress in the bond line edges. Strength is thus the critical parameter for designing composite patch repairs,

However, the resistance determination of the patch will induced difficulties to produce a reliable design method, many obstacles are inbound in the nature of composite patch repair for steel structure:

- materials discontinuity (material properties)

- $\quad$ Nonlinear material properties of the adhesive,

- $\quad$ Singularity at the edge of the patch.

The different toughness properties of each the adhesive, and each interface involved in the patch be assessed through classical fracture mechanics investigations, using standardized tests, such as the ENF (End Notched Flexure) (ASTM D7905), or DCB (Double Cantilever Beam) (ASTM D5528), and analysed using simple theories based on linear elastic fracture mechanics.

The following sections of the paper describe the experimental that was carried out for the ENF test. Firstly, the studied specimens (steel bonded to steel), and the used test bed geometries based on the ones described in ASTM standards (D7905, 2014) are presented. Then, the monitoring (distributed optical fibre sensor and digital image correlation) used to compute the local strain measurement, load and local displacement curve are expressed. The local strain measurement is supposed to capture the position of the crack front at its maximum value. This assumption is then compared to an analytical model to set a new crack front position using a distributed optical fibre sensor bonded outside of the sample (preventing from embedding brittle optical fibre inside of the bonded samples). Distributed optical fibre crack front are then used to compute the critical toughness in mode II, $G_{I I C}$. This is finally compared to non-standard methods as described in (Girolamo 2015) or (Leffler 2007).

\section{Experimental investigation}

\section{Studied specimens}

In ASTM D7905 standard (ENF test), three standard test procedures are proposed to characterize the interlaminar fracture toughness in mode II for unidirectional carbon fibre reinforced polymer CFRP materials. For simplification reason, the standard samples geometries proposed in the ASTM D7905 proposed for UD $0^{\circ}$ CFRP have been increased by a factor 2 and the substrate has been changed by a steel plate, as shown in Figure 1a, in order to study the mechanics of adhesive failure. In order to obtain an initial crack front, soap and a Teflon insert have been placed between the steel plates. The dimensions of the samples are shown in figure 1a. The used steel plates are S355 and the adhesive is a cold curing epoxy (Sikadur 30). The main properties of this adhesive are given in Table 1 (technical data sheet). Steel surfaces were sanded and degreased prior to bonding. The sample was then cured at $20^{\circ} \mathrm{C}$ during seven days before being tested.

Table 1. Sikadur 30 material properties in tension

\begin{tabular}{ccc}
\hline $\begin{array}{c}\text { Young } \\
\text { modulus }\end{array}$ & $\begin{array}{c}\text { Tensile } \\
\text { stress }\end{array}$ & $\begin{array}{c}\text { Strain at } \\
\text { break }\end{array}$ \\
\hline $11 \mathrm{GPa}$ & $25 \mathrm{MPa}$ & $1 \%$ \\
\hline
\end{tabular}




\section{Test geometry}

The test frames have also been adapted to the new samples geometry (compared to the one proposed by the ASTM D7905). The increase in length and width implied increasing the overall size of the assembly (Figure 1b) as in (Tsokanas, 2018). Similarly, the initial crack length has been increased compared to the ASTM standard, to ensure that the crack propagation remains under control, as too little initial crack length can tend to uncontrolled crack propagation (Allix 1995). The load application is carried out according to (ASTM D7905) at a constant speed of $2 \mathrm{~mm} / \mathrm{min}$.

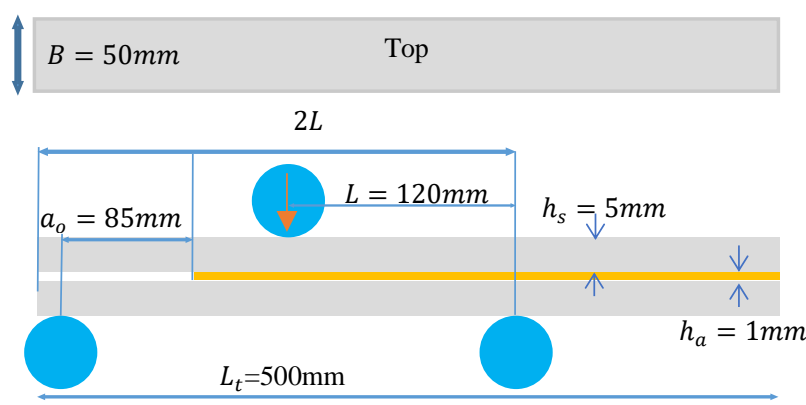

a)

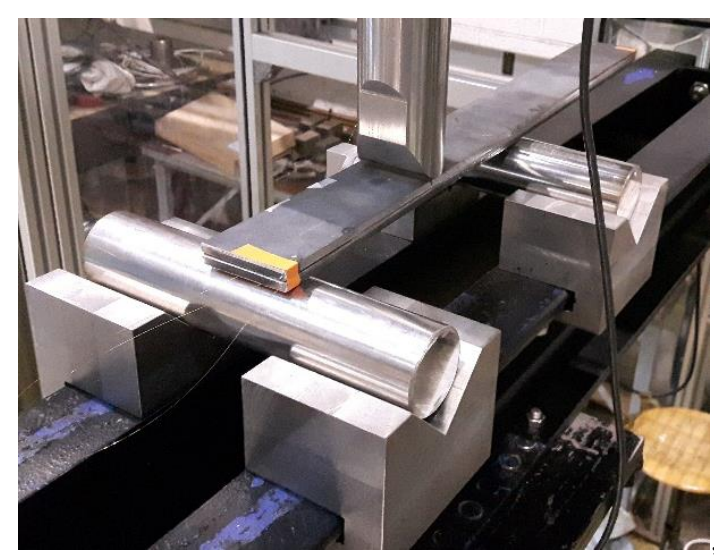

b)

Figure 1. a) ENF Test configuration, b) Photo of the ENF sample and test bed

\section{Monitoring during the test:}

Applied force and displacement are monitored during the whole test with a $5 \mathrm{kN}$ load cell (precision \pm $0.145 \%$ ) and the jack displacement sensor (precision 10 $\mu \mathrm{m}$ ). In addition, two local monitoring methods are used (continuous optical fibre and digital image correlation).

\section{Digital image correlation}

A black and white speckle has been deposited on the test specimen by non-homogeneous spraying of paint in three successive layers (white / black / white). The cameras were adjusted following the Corelli@) software procedure (brightness/sharpness/calibration/synchronization) (see Figure 3a). The position of the cameras (distance to the samples), was settled in order to monitor a size corresponding to $6 \mathrm{~cm} \mathrm{x} 2 \mathrm{~cm}$ around the initial crack location. The measurement accuracy is directly related to the size of the area of interest. For this application, the used mesh was 32 pixel *32pixel allowing to have a measurement resolution of $0.5 \mathrm{~mm}$. The local displacement measurement is $5 \mu \mathrm{m}$ and the recording frequency is $5 \mathrm{~Hz}$.

\section{Continuous optical fibre}

The capacity to obtain, in real time, nearly continuous data, such as strain, pressure or even temperature in materials, with only one optical fibre of length up to ten meters is really attractive. In addition, the relatively small size of some optical fibre allows them to be integrated directly in an assembly (Guo 2011) as bonded or composite structures (Murayama H, 2011) with limited impact on the overall resistance (Meadows 2017). For these reasons, distributed optical fibre sensors were used to collect measurements along the entire length of the fibre. A tuneable frequency laser is used to measure the unique backscattering light along the fibre. Physical changes (as temperature or displacement) induce the fibre to contract or expand changing the Rayleigh pattern and the backscattering. To convert these changes into physical values, the measurement signal, returned from the fibre, is divided into small areas $(\geq 1 \mathrm{~mm}$ ) (Samiec, 2012). The used Optical Distributed Sensor Interrogator is a Luna ODiSI-B (Luna). It allows the strain measurement long a fibre, up to $10 \mathrm{~m}$ long with maximal spatial resolution of $1.2 \mathrm{~mm}$. It was set at a frequency of $12 \mathrm{~Hz}$, recording the strain during all the test, and all along the bonded optical 
fibre. The measurement noise can vary depending of many parameters that will not be discussed here. In our case, the recorded noise before the test was +/- $20 \mu$ strain.

For our test specimens, a $150 \mu \mathrm{m}$-diameter optical fibre with polyimide coating was bonded in several locations as shown in Figure 2:

- On the test specimen upper surface: in the centre with Araldite 2014-2 adhesive.

- Inside the bond line: in the centre inside the adhesive Sikadur 30.
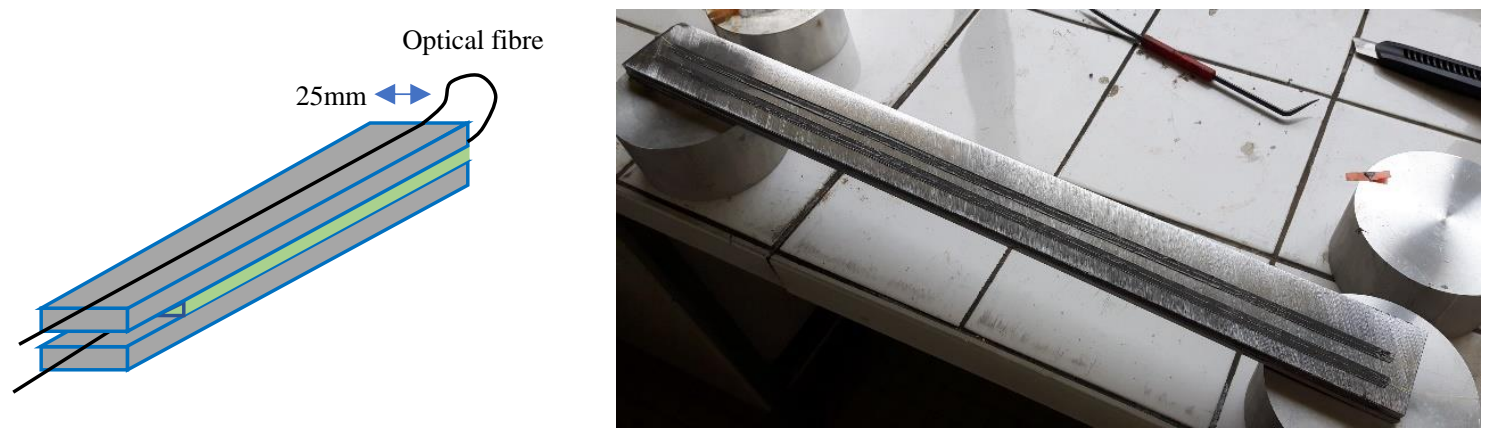

Figure 2. Position of the optical fibre and example of optical fibre application on specimen

The disposition of the sample on the test was made in such a way that the exterior optical fibre was underneath the sample (and was under traction loading during the test). A photo of the overall test setting with both local measurement methods is given in Figure $3 b$.
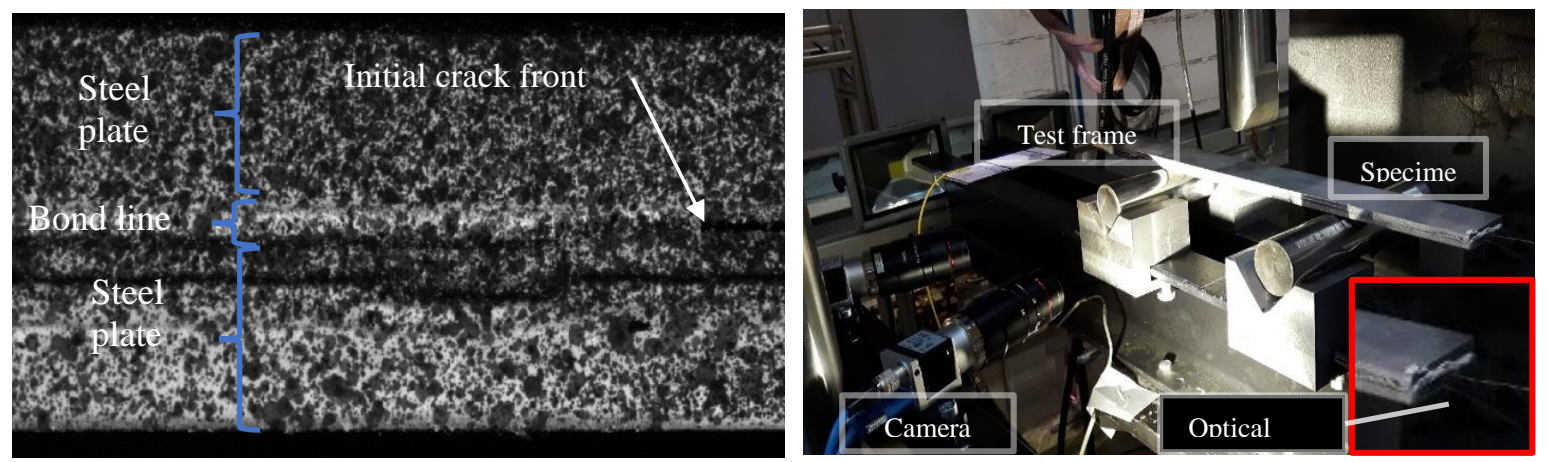

Figure 3. a) Speckle and initial crack, b) ENF specimen, instrumentation and test frame

\section{Experimental results analysis}

\section{Load displacement curve}

The obtained load-displacement curve is shown in figure 4 . Three stages can be observed. The first one is a linear elastic stage up to point A. Once the load exceeds the point of proportional limit, damage appears in the bondline, extends and forms the fracture process zone (FPZ) which leads to a slope decrease, and an increase of the compliance. When the FPZ is fully developed, the load-displacement curve reaches its maximum point (point $B$ on figure 4) and the crack propagation begins. The crack propagation is assumed to occur up to the local minimum after the first load decrease (between $\mathrm{B}$ and $\mathrm{C}$ on figure 4). This corresponds to time periods: $\mathrm{B}=58 \mathrm{~s}$ to $\mathrm{C}=68 \mathrm{~s}$. Consequently, the upcoming analysis will be focused on the results computed between these two time periods. 


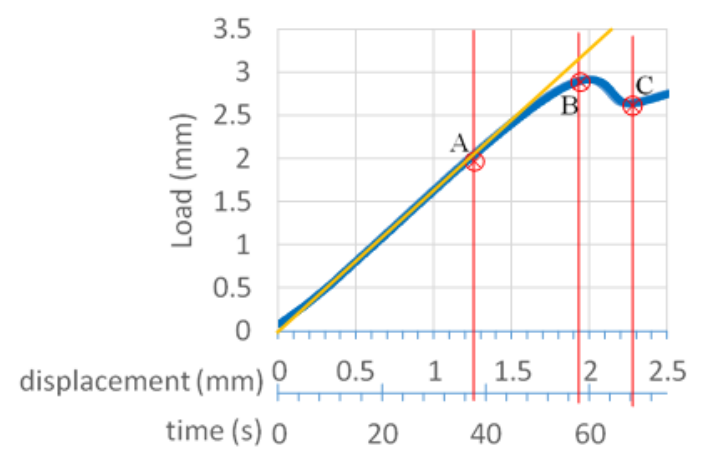

Figure 4. Load displacement curve

\section{Embedded optical fibber}

Before the crack propagation (i.e. before point B), the resulting curve for the optical fibre inserted inside the bond layer (Figure 5) presents an initial peak value which is understood as the position of the initial crack front at the same location. Along the test duration, this initial strain jump remains at the initial crack front position, but with a different shape upstream. The experimental result shows a strain plateau with a length of $1 \mathrm{~mm}$ at the beginning of the non-linearity (at point A) on the Figure 4. This plateau increases up to $14 \mathrm{~mm}$ at the moment of the initial crack propagation (at point $\mathrm{B}$ ). This is assumed to be linked to damage near the crack tip before its propagation, and could thus be used as a measurement of the fracture process zone (FPZ) length. Further tests with cohesive zone model will be performed in the next steps of the Strength Bond project to validate this assumption. After the initial crack propagation (figure 6), no really visible indication is left by the fibre measurement to monitor the crack front position during the test. This result seems to indicate an incapacity to follow the crack propagation using only the embedded optical fibre. Further study will be carried out on this issue.

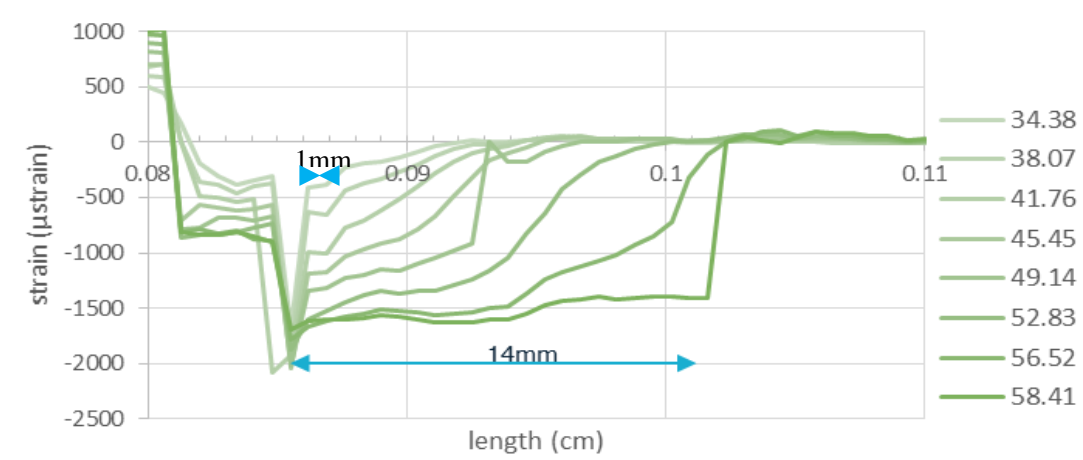

Figure 5. Embedded distributed optical fibre strain measurement before 58s

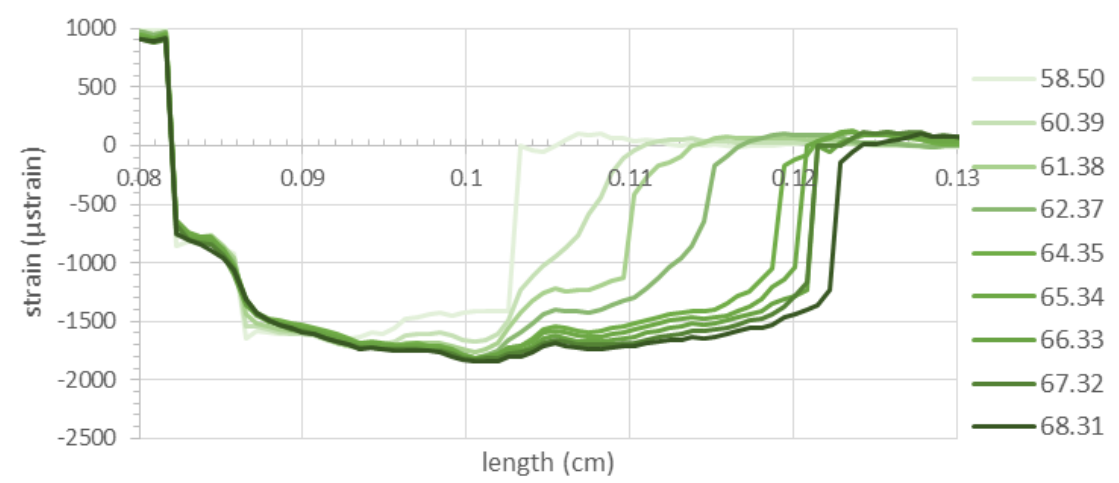

Figure 6. Embedded distributed optical fibre strain measurement after $58 \mathrm{~s}$ 


\section{Exterior optical fibre}

Upstream of the crack front, the sample corresponds to a beam of thickness $2 * h_{s}+h_{a}\left(h_{s}\right.$ and $h_{a}$, the steel and adhesive thickness) while downstream of the crack front, the sample is equivalent to the superposition of two beams of thickness $h_{s}$ (neglecting the friction). Then, following the beam theory, the measured strain $\varepsilon_{x x 1}$ and $\varepsilon_{x x 2}$, respectively the upstream, and downstream surface strain of the sample follows the equation (1) and (3) which are maximal at the junction of the bonded and un-bonded beams for the equation (1) (corresponding to the location of the crack tip) and at the load application point for the equation (3). This analysis, relies on one important assumption: the supposed plasticity/damaged detected inside the bondline (FPZ size) using the embedded optical fibre, has limited impact on the exterior fibre measurement.

$$
\varepsilon_{x x 1}=-\frac{M_{f z}}{2 E_{s} I_{h z 1}} h_{s}
$$

With $M_{f z}$ the bending moment, $E_{s}$ the steel Young's modulus, $h_{s}$ the steel plate thickness and $I_{h z 1}(2)$ the moment of inertia of the steel plate.

$$
I_{h z 1}=\frac{B h_{s}^{3}}{12}
$$

With $h_{s}$ the steel thickness

$$
\varepsilon_{x x 2}=-\frac{M_{f z}}{<E I_{h z 2}>}\left(\frac{h_{a}}{2}+h_{s}\right)
$$

With $<E I_{h z 2}>(4)$ being the equivalent stiffness of the bonded plate and $h_{a}$ the adhesive thickness

$$
<E I_{h z 2}>=\frac{2 E_{S} B}{3}\left(\left(\frac{h_{a}}{2}+h_{s}\right)^{3}-\frac{h_{a}{ }^{3}}{2}\right)+\frac{2 E_{a}}{3} h_{a}{ }^{3}
$$

With $E_{a}$ the adhesive Young's modulus

The position of the crack tip is then supposed to be related to the maximum strain value measured with the optical fibre. Figure 7 presents the strain measurement along the length of the sample for the exterior optical fibre placed at mid-width of the sample during the crack propagation. Each curve corresponds to a different time.

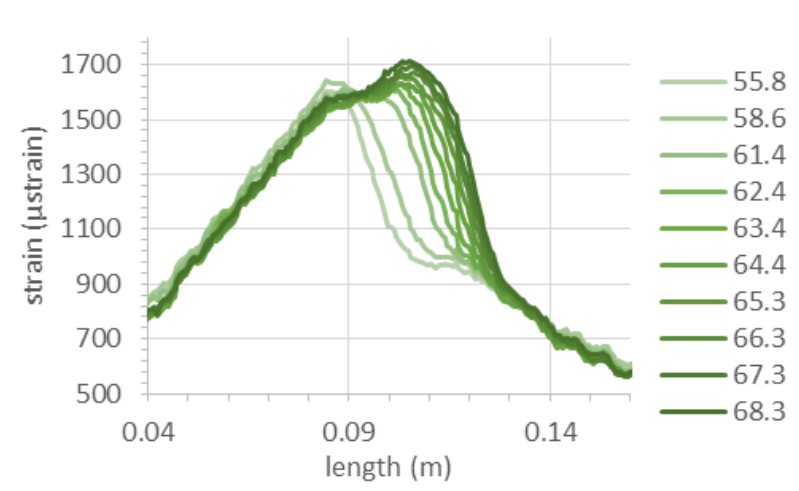

Figure 7. Exterior optical fibre continuous strain measurement between time $58 \mathrm{~s}$ and $68 \mathrm{~s}$

Thus, it can be checked that position $\sim 0.085 \mathrm{~m}$ corresponds to the initial crack length. Figure $8 \mathrm{a}$ represents the optical fibre strain measurement maximal values versus the axial length for different times 
between point $\mathrm{B}$ and $\mathrm{C}$. We can observe a shift of the maximum of the curve to the right, indicating a propagation of the crack tip. The study of the displacement of this peak is then used to monitor crack propagation. The resulting curve (Figure $8 b$ ) of the position of the maximum strain vs time shows that the main crack propagation occurs between 62 and 64 seconds. This confirms the fact that the global crack propagation occurs between $\mathrm{B}$ and $\mathrm{C}$. A post processing of the data have been made to reduce the raw crack front computation noise for the following computation (moving average of the 5 data points centered on the original value).

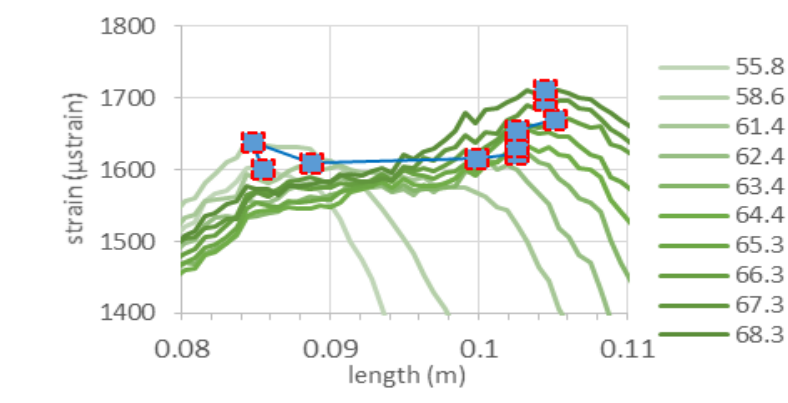

a)

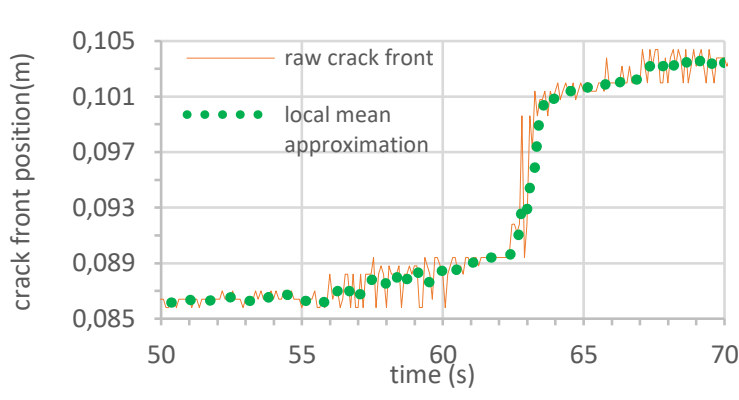

b)

Figure 8. a) Maximum locations of the optical fibre strain measurement. b) Crack propagation curve for the ENF test - data processing via local mean approximation.

The exterior optical fibre shows good results, with a maximum strain value being located right above the crack front. Yet, it must be pointed out that the analysis of the position of the maximum of the exterior optical fibre strain as a direct measurement of the crack front position might have some limitations. The not well defined location of the maximal value (compared with the inner optical fibre) combined with the optical fibre measurement noise ( $+/-20 \mu$ strain) can indeed tend to generate uncertainties on the crack front position. To ensure a correct initial position, the inner optical fibre seems to be more precise and relevant, as the initial crack front peak can be clearly identified. It was thus decided to measure the initial position of the crack front with the inner optical fibre, and to monitor the crack propagation with the exterior optical fibre during the whole test.

\section{Strain Energy release rate computation with standards}

\section{The Compliance Calibration Method (CCM)}

The CCM (Banea 2008) is a widely used method for calculating the rate of release of critical strain energy. During the test, the load, applied displacement and crack length (P- $\delta$-a) are recorded in order to calculate the critical strain energy release rate using the Irwin-Kies equation (2) (Kanninen 1985). For the ENF test, it has been proposed in (Davies 2001) to express the compliance as a cubic function of the crack length $a$, as in equation (3). $G_{I I C}$ can then be expressed as in equation (4). This approach requires "calibration" of compliance as a cubic function of crack length, normally done with multiple samples (at least 3) of different initial crack length. In our case, it is directly obtained with the crack propagation curve measured with the optical fibre during the test. This approximation being highly dependent on the crack length measurement, especially for limited crack propagation length such as in ENF test, it can lead to error if the crack front isn't monitored properly, or if the initial crack front is not well defined.

$$
G_{I I C}=\frac{P^{2} d C}{2 B d a}
$$

With $\mathrm{P}$ the applied load, B the width of the specimen, $\mathrm{C}$ the compliance and $a$ the crack length.

$$
C=D+m a^{3}
$$

With D and m constant values. 


$$
G_{I I C}=\frac{3 P^{2} m a^{2}}{2 B}
$$

The following curves represent the results of calculations obtained using equations 2 and 3. Using Davies' formula with the previously obtained parameter $m$ (Figure 9a) gives the curve in Figure 9b, with a stabilization around the value $0.87 \pm 0.02 \mathrm{~kJ} / \mathrm{m}^{2}$.

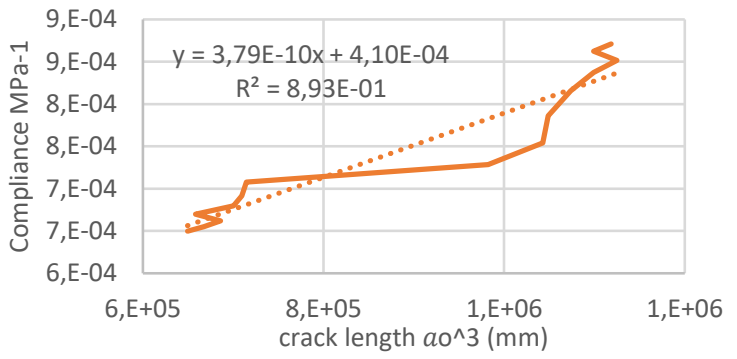

a)

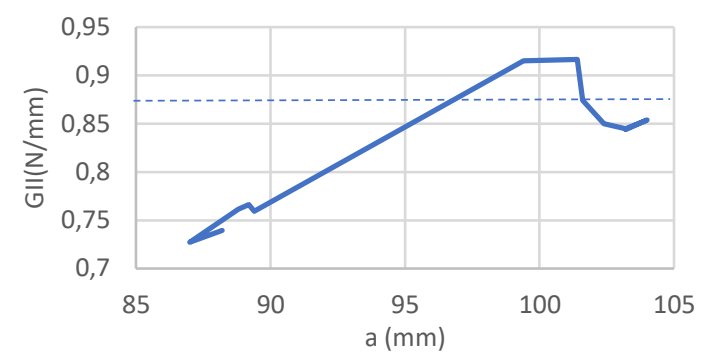

b)

Figure 1. a) Cubic $C=f\left(a^{3}\right)$ approximation, and linear regression, b) GII computation with Davies approximation

\section{ASTM D7905 CCM approximation}

The ASTM standard (D7905) proposes another approach following the compliance calibration. It does not need to monitor the crack propagation, but requires a higher number of samples and tests with different initial crack front length to establish the relation $C=f(a)$, which is regressed using the same cubic function as in paragraph 6.a. This approach is based on the same theory, but assuming that crack propagation only takes place when the force has reached its peak, leading to the equation (5). In our case, this computation has be done measuring the crack length during propagation.

$$
G_{I I C}=\frac{3 P_{\max }^{2} m a_{0}^{2}}{2 B}
$$

Likewise, the use of formula (5) with the values $P_{\max }=2900 \mathrm{~N}, a_{0}=85 \mathrm{~mm}$ (obtained with the embedded optical fibre), and $\mathrm{m}=3.79$ (obtained with exterior optical fibre) allows obtaining the value $G_{\text {IIC }}=0.71$ $\mathrm{kJ} / \mathrm{m}^{2}$. This result must be taken with care as only sample was tested in this study. This value is lower than the one obtain with the CCM computation. This may be due to the fact that when taking into account the maximum force value, one neglects the need for the crack propagation to stabilize, as the initial crack front is artificially created by the Teflon insert. This may tends to underestimate the corrected crack length and therefore the critical toughness.

\section{Local sliding and J-integral}

The above methods can only be used in cases when linear elastic fracture mechanics (LEFM) theory can be applied, which assumes that there is limited material non-linearity in the adhesive. Therefore, data reduction techniques neglect the impact of the process zone upstream of the crack front. This can lead to inaccurate $G_{I I C}$ for materials that develop a rather large process zone compared to the overall size of the samples. The J-integral is a technique used for calculating the fracture energy for problems where the assumptions of the LEFM are no longer valid. It is defined by a contour integral whose value is equal to the energy release rate. Rice (Rice, 1968) has shown that for monotonic loading, with crack propagation occurring in homogenous material, the J-integral is path independent and its value is equal to the energy released during the damage process for linear and nonlinear elastic body. Those two properties allow us to select the most convenient path to integrate the stresses and to compute the energy release rate from common tests, as ENF one. Different analytical expressions of the J-integral can be found in literature. Leffler (Leffler, 2007) proposed the equation (6) following the LEFM for ENF test that has shown good results in several studies, as in (Girolamo 2015) for cohesive law calibration of 
multi-layered composites double lap joint. It must be specified that in this equation, the first term is obtained via the beams theory for a rigid adhesive and that the second term corresponds to the effect of the flexibility of the adhesive. This effect proved to be non-negligible in our case as local sliding was measured using the DIC measurement.

$$
J_{E N F}=\frac{9}{16} \frac{\left(P a_{0}\right)^{2}}{E h_{s}{ }^{3} B^{2}}+\frac{3 \delta_{s}}{8 h_{s} B}
$$

With $\mathrm{P}$ the load, $a_{0}$ the initial crack length, $\delta_{s}$ the local sliding (Figure 10), E the adherent young modulus, $h_{s}$ the adherent thickness and B the sample width.

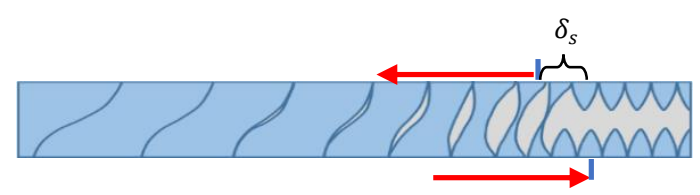

Figure 2. ENF local sliding at the crack front.

To determine J-ENF values, the DIC system was used to measure the displacement fields on the profile of the specimens at the crack tip during the test. Figure 11a shows the meshing and local displacement performed by the DIC software. The obtained J-integral curve is given in Figure $11 \mathrm{~b}$. Using equation 6 , it is then possible to determine the toughness value at stabilization which is $G_{I I C}=0.8 \mathrm{~kJ} / \mathrm{m}^{2}$.
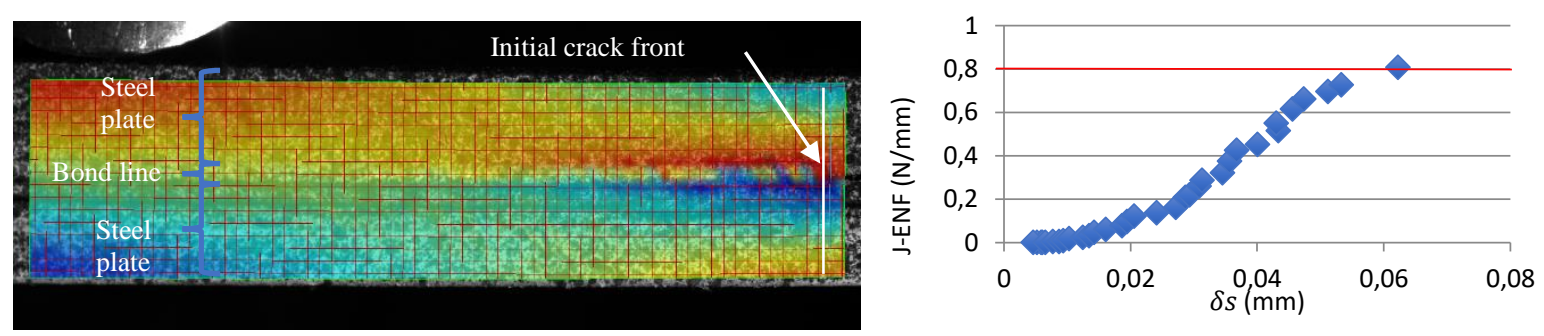

Figure 11. a) Stereo-correlation data analysis, b) ENF J-integral vs displacement jump

All the obtained results (critical toughness) with the three presented methods are given in Table 4. It can be seen that the three values are very close, indicating consistency of the three approaches. It can be noted that the value determination using the ASTM approach is $20 \%$ lower. This is due to the fact that when taking into account the maximum force value, one neglects the need for the crack propagation to stabilize. This tends to underestimate the corrected crack length and therefore the critical toughness.

Table 2: Results regarding the determination of $G_{I I C}$

\begin{tabular}{lc}
\hline Model & $G_{I I C}\left(\mathrm{~kJ} / \mathrm{m}^{2}\right)$ \\
\hline (Davies 2001) & $0.87 \pm 0.02$ \\
(ASTM 2014) & 0.71 \\
(Leffler 2007) & 0.8 \\
\hline
\end{tabular}

\section{Conclusion}

This study investigated the use of optical fibre to measure the crack propagation and determine the critical toughness in ENF test. It was shown that the high spatial resolution and the accurate strain measurement of the optical fibre can be useful to the analysis of ENF test. The optical fibre being located inside the specimen enable to determine very precisely the initial crack front and the external fibre can be used to determine the crack front propagation during the test. In addition, the central position of the exterior optical fibre is supposed to reduce error in crack front position compared to more commonly 
used methods such as DIC or visual inspection that are highly dependent of the crack front shape (both those methods are carried out on the side of the sample).

This measurement technic together with some hypotheses (LEFM) allowed determining the critical toughness of the bonded joint. The obtained results with three different theories are very close, indicating a good consistency of the different approaches. In addition, it was shown that the inside optical fibre allows to monitor the stress state inside the bondline and to give information on the process zone length during the test.

Additional investigations are currently realized to use such crack monitoring techniques in other fracture mechanics investigations: DCB and MMB tests. The analysis of the optical fibre measurement along the process zone will also be further investigated comparing it with the results of non-linear Finite Element Models relying on the use of cohesive zone elements.

\section{Bibliography}

Allix, O. \& Ladeveze, P \& Corigliano, A. (1995). Damage analysis of interlaminar fracture specimens. Composite Structures. 31. 61-74.

Banea, M \& da Silva, LFM (2009). Adhesively bonded joints in composite materials: An overview. Proceedings of The Institution of Mechanical Engineers Part L-journal of Materials-design and Applications - PROC INST MECH ENG L-J MATER. 223. 1-18.

D7905. (2014) Standard test method for determination of the mode II interlaminar fracture toughness of unidirectional fiber-reinforced polymer matrix composites. West Conshohocken, PA: ASTM International

Davies.P (2001) Fracture Mechanics Testing Methods for Polymers, Adhesives and Composites, Adhesives and Composites, Chapter: Introduction to delamination fracture of continuous fibre composites elsevier Science. 28. 271-275

Girolamo, D \& Dávila, C \& Leone, F \& Lin, S-Y. (2015). Cohesive Laws and Progressive Damage Analysis of Composite Bonded Joints, a Combined Numerical/Experimental Approach. 56th AIAA/ASCE/AHS/ASC Structures, Structural Dynamics, and Materials Conference

Guo, H \& Xiao, G \& Mrad, N \& Yao, J. (2011). Fiber Optic Sensors for Structural Health Monitoring of Air Platforms. Sensors (Basel, Switzerland). 11. 687-705

Kanninen M.F (1985) Advanced Fracture Mechanics. Oxford University Press.

Leffler, K \& Alfredsson, Svante \& Stigh, Ulf. (2006). Shear behaviour of adhesive layers. International Journal of Solids and Structures - INT J SOLIDS STRUCT. 44

LUNA. OdisiB. (2020). http://lunainc.com.

Meadows, L \& Sullivan, R\& Brown, K \& Ranatunga, V \& Vehorn, K \& Olson, S. (2017). Distributed optical sensing in composite laminates. The Journal of Strain Analysis for Engineering Design. 52

Murayama, H \& Kageyama, K \& Uzawa, K \& Ohara, K \& Igawa, H. (2011). Strain monitoring of a single-lap joint with embedded fiber-optic distributed sensors. Structural Health Monitoring. 11. 325344

Tsokanas, P \& Loutas, T \& Kostopoulos, V \& Essa, Y \& Escalera, F. (2018). On the design and analysis of interlaminar fracture toughness tests on dissimilar metal-composite adhesive joints with residual thermal stresses. Conference: ECCM18, 18th European Conference on Composite MaterialsAt: Athens, Greece

Rice, J. (1968). A path independent integral and the approximate analysis of strain concentration by notched and cracks. J Appl Mech. 35.

Samiec D. (2012). Distributed Fibre-Optics Temperature and Strain Measurement with Extremely High Spatial Resolution: Photonik International. 1. 10-13 